Table 2. Multivariate analysis for hand grip strength and SMI in patients with Sjogren's syndrome

\begin{tabular}{ccccc}
\hline $\begin{array}{c}\text { Unstandardized } \\
\text { Coefficients }\end{array}$ & $\begin{array}{c}\text { 95\% Confidence } \\
\text { Interval for B }\end{array}$ & $\begin{array}{c}\text { Standardized p-value } \\
\text { Coefficients }\end{array}$ \\
\hline B & $\begin{array}{c}\text { Std. } \\
\text { Error }\end{array}$ & Lower & Upper & Beta \\
\hline & Erat & & \\
\hline
\end{tabular}

\begin{tabular}{lllllll}
\hline $\begin{array}{l}\text { Hand grip } \\
\text { strength }\end{array}$ & & & & & & \\
$\begin{array}{l}\text { Constant } \\
\text { ESSPRI pain }\end{array}$ & 24,492 & 1,695 & 21,071 & 27,914 & - & $<0.001$ \\
SMI & $-0,707$ & 0,282 & $-1,276$ & $-0,139$ & $-0,361$ & $\mathbf{0 , 0 1 6}$ \\
Constant & 5,419 & 1,705 & 1,978 & 8,860 & - & $\mathbf{0 . 0 0 3}$ \\
MNA & 0,380 & 0,127 & $-1,276$ & $-0,139$ & 0,419 & $\mathbf{0 , 0 0 5}$ \\
\hline
\end{tabular}

ESSPRI: EULAR Sjogren's Syndrome Patient Reported Index, SMI: Skeletal Muscle Index MNA: Mini Nutritional Assessment

Conclusion: Risk of sarcopenia is increased in patients with SS. In the current study, it is shown that pain is related with sarcopenia. ESPPRI pain is a sign of continuing chronic inflammation in patients with SS. Malnutrition, which can indirectly related with SS, may also contribute to this process. Excessive pain may lead to decrease daily activities and nutritional status of patients with SS. Evaluating pain and patient's global disease activity may help physicians to find out patients with increased risk for sarcopenia. Controlling disease activity and pain and preventing malnutrition may reduce the risk for development of sarcopenia.

Acknowledgments : None to declare

Disclosure of Interests: : None declared

DOI: 10.1136/annrheumdis-2020-eular.4918

\section{AB0405 ABNORMAL BLOOD LIPID METABOLISM IN PREMENOPAUSAL FEMALE SYSTEMIC LUPUS ERYTHEMATOSUS PATIENTS IS RELATED TO HYPERURICEMIA AND PROTEINURIA}

H. Liu', J. Z. Lin ${ }^{2}$, X. Cai ${ }^{3}$, J. D. MA ${ }^{2}$, Y. Mo ${ }^{2}$, M. Xie ${ }^{1}$, L. Dai ${ }^{2}{ }^{1}$ Panyu Central Hospital, Department of Rheumatology, Guangzhou, China; ${ }^{2}$ Sun Yat-Sen Memorial Hospital, Sun Yat-sen University, Department of Rheumatology, Guangzhou, China; ${ }^{3}$ Guangzhou First People's Hospital, The Second Affiliated Hospital of South China University of Technology, Department of Rheumatology, Guangzhou, China

Background: 1. Hyperuricemia is often associated with abnormal lipid metabolism. We reported premenopausal female systemic lupus erythematosus (SLE) patients had elevated blood UA levels ${ }^{[1]}$. Do these patients also have hyperlipidemia?

2. Estrogen has certain effect on blood lipid metabolism, whether the blood lipid levels of premenopausal female SLE patients who have the background of hyperestrogen function are affected by estrogen and its receptors?

Objectives: To investigate the relationships between blood lipids and serum UA level, estrogen receptors (ERs) as well as ER antibodies in premenopausal female SLE patients.

Methods: 123 premenopausal female SLE patients (SLE group) were divided into normal $\mathrm{CH}$ group $(\mathrm{n}=93)$ and high $\mathrm{CH}$ group $(\mathrm{n}=30, \mathrm{CH}>5.17 \mathrm{mmol} / \mathrm{l})$, and 40 healthy premenopausal females served as the control group. The blood lipid levels of the SLE group and the control group were compared, and the blood levels of lipid, UA, estrogen, ERs and ER antibodies were compared between the two SLE subgroups. Linear regression was used to analyze the influencing factors of blood $\mathrm{CH}$.

Results:

1. In SLE group, the blood level of TG was significantly higher than that of the control group $(1.67 \pm 1.10$ vs. $0.87 \pm 0.47, P<0.001)$, while the levels of blood $\mathrm{CH}$, LDL, HDL were comparable to the control group (all with $\mathrm{P}>0.05$ ).

2. The mean blood $\mathrm{CH}$ level of the SLE patients with hyperuricemia was $5.57 \pm$ $2.44 \mathrm{mmol} / \mathrm{l}$, which was significantly higher than that of patients with normal UA level $(3.98 \pm 1.30 \mathrm{mmol} / \mathrm{l}, \mathrm{P}<0.001)$.

3. The serum UA, CRE, CH, TG, LDL, and 24-hour urinary protein quantification (24h UPRO) in the high CH SLE subgroup were significantly higher than those in the normal CH SLE subgroup (all with $P<0.05$ ). There were no significant differences in serum estrogen, ERs and ER antibodies between the two subgroups, Table 1.

4. Linear regression showed that serum UA level and $24 \mathrm{~h}$ UPRO were the dangerous effects of elevated blood $\mathrm{CH}$ in the premenopausal female SLE patients, Table 2

Conclusion: Compared with healthy female of the same age range, the premenopausal female SLE patients are more likely to have abnormal lipid metabolism, which is related to kidney damage and abnormal UA metabolism.

\section{References:}

[1] Haijun Liu, Xiaoyan Cai, Lie Dai, et al. Elevated uric acid levels in premenopausal female systemic lupus erythematosus patients: association with potential or existing renal damage. Eur J Inflamm,2018,16:1-6.

Table 1. Some clinical indicators, estrogen, ERs and ER antibodies in the premenopausal female SLE patients

\begin{tabular}{lccc}
\hline & $\begin{array}{c}\text { High } \mathbf{C H} \text { group } \\
(\mathbf{n}=\mathbf{3 0})\end{array}$ & $\begin{array}{c}\text { Normal } \mathbf{C H} \text { group } \\
(\mathbf{n}=93)\end{array}$ & $\mathbf{P}$ \\
\hline Age(years) & $31.40 \pm 7.40$ & $28.12 \pm 7.23$ & 0.039 \\
$\mathrm{UA}(\mu \mathrm{mol} / \mathrm{l})$ & $433.40 \pm 192.90$ & $310.10 \pm 129.57$ & 0.002 \\
$\mathrm{CRE}(\mu \mathrm{mol} / \mathrm{l})$ & $112.07 \pm 87.09$ & $72.81 \pm 91.96$ & 0.039 \\
$\mathrm{CH}(\mathrm{mmol} / \mathrm{l})$ & $7.07 \pm 2.05$ & $3.72 \pm 0.93$ & $<0.001$ \\
$\mathrm{TG}(\mathrm{mmol} / \mathrm{l})$ & $2.27 \pm 1.57$ & $1.48 \pm 0.84$ & 0.013 \\
$\mathrm{LDL}(\mathrm{mmol} / \mathrm{l})$ & $4.48 \pm 1.46$ & $2.29 \pm 0.67$ & $<0.001$ \\
$\mathrm{HDL}(\mathrm{mmol} / \mathrm{l})$ & $1.02 \pm 0.72$ & $1.97 \pm 0.43$ & 0.721 \\
Estrogen $(\mathrm{pg} / \mathrm{ml})$ & $73.53 \pm 47.74$ & $69.42 \pm 55.48$ & 0.717 \\
ERa(pg/ml) & $45.94 \pm 31.06$ & $43.34 \pm 31.05$ & 0.684 \\
ER $\beta(\mathrm{pg} / \mathrm{ml})$ & $16.65 \pm 28.67$ & $13.70 \pm 25.09$ & 0.589 \\
Anti-ERa(ng/ml) & $59.75 \pm 33.87$ & $55.16 \pm 31.34$ & 0.496 \\
Anti-ER $\beta(\mathrm{ng} / \mathrm{ml})$ & $89.73 \pm 49.03$ & $71.73 \pm 41.74$ & 0.052 \\
$24 \mathrm{~h}$ UPRO(g/24h) & $2.82 \pm 3.82$ & $0.39 \pm 0.56$ & 0.002 \\
Positive UBLD(\%) & $20(66.67)$ & $31(33.33)$ & 0.01 \\
SLEDAl & $13.18 \pm 4.23$ & $7.39 \pm 6.18$ & 0.025 \\
\hline
\end{tabular}

ER, estrogen receptor; 24h UPRO, 24-hour urinary protein quantification; UBLD, urinary blood.

Table 2. Relationships between blood $\mathrm{CH}$ level and clinical indicators in in the premenopausal female SLE patients

\begin{tabular}{|c|c|c|c|c|c|c|}
\hline Variable & $\begin{array}{l}\text { Unstandardized } \\
\text { Coefficients }\end{array}$ & & $\begin{array}{l}\text { Standardized } \\
\text { Coefficients }\end{array}$ & $t$ & $\mathbf{P}$ & $95 \% \mathrm{Cl}$ \\
\hline & B & SEM & & & & \\
\hline 24h UPRO & 0.353 & 0.072 & 0.400 & 4.932 & $<0.001$ & $0.211 \sim 0.495$ \\
\hline & 0.003 & 0.001 & 0.249 & 3.058 & 0.003 & $0.001 \sim 0.005$ \\
\hline Constant & 3.146 & 0.359 & & 8.754 & $<0.001$ & 2.434 3.857 \\
\hline
\end{tabular}

UA, uric acid; 24h UPRO, 24-hour urinary protein quantification.

Disclosure of Interests: : None declared

DOI: 10.1136/annrheumdis-2020-eular.2696

\begin{tabular}{|l|l|}
\hline AB0406 & HUMAN PAPILLOMA VIRUS (HPV) VACCINATION \\
SAFETY IN SYSTEMIC LUPUS ERYTHEMATOSUS \\
COHORT - PORTUGUESE UNIVERSITY HOSPITAL \\
SINGLE-CENTER COHORT STUDY
\end{tabular}

J. Sousa Morais ${ }^{1}$, D. G. Oliveira ${ }^{2}$, R. Faria ${ }^{3,4}$, A. Almeida ${ }^{3}$, M. Brandão $0^{3,4}$ A. Marinho ${ }^{3,4}$, I. Almeida ${ }^{3,4}$, F. Farinha ${ }^{3}$, C. Vasconcelos ${ }^{3,4} .{ }^{1}$ Serviço de Medicina, Hospital de São Marcos, Braga, Portugal; ${ }^{2}$ Serviço de Medicina, Porto, Portugal; ${ }^{3}$ Unidade de Imunologia Clínica, Porto, Portugal; ${ }^{4}$ Abel Salazar Biomedical Sciences Institute - University of Porto, UMIB, Porto, Portugal

Background: Cervical cancer is a potentially preventable consequence of Human Papillomavirus (HPV). HPV vaccination is recommended in most countries for all young women, preferentially before sexual activity begins. In Portugal, HPV vaccination is available in either bivalent (genotypes 6,18 ) or tetravalent $(6$, 11,16 e 18) vaccines. Both have aluminum as an adjuvant, a substance arguably capable of inducing inflammatory adjuvant syndromes. Systemic Lupus Erythematosus (SLE) mostly afflicts women of childbearing age, the very target population for HPV vaccination. There are conflicting reports in the literature regarding both the efficacy and safety of this vaccine in SLE patients. This question is particularly pressing as HPV infection prevalence seems to be increased in SLE patients.

Objectives: To analyze the safety of HPV vaccination in a SLE patient cohort followed at a university hospital.

Methods: Retrospective single-center (35 year long, 436 SLE patient cohort) review of all female SLE patients' local and online national records on HPV vaccination and cervical cancer screening. Data on activity (using SLEDAI-2K scoring) and concomitant drug use were reviewed for the two years before and after vaccination date.

Results: Of the 463 SLE patients, 420 were women (91\%), of which 322 had clinical information about yes/no HPV vaccination. Twenty-seven of the patients $(8 \%)$ had one of HPV vaccines, but only $13(4 \%)$ had full information on activity before and after vaccination. Mean current age was 33,8 years and a minimum of 8,4 years of follow-up after HPV vaccination. Twenty-there $(85 \%)$ were vaccinated with the tetravalent vaccine. Pre-vaccination mean SLEDAI score of was 5.9: due to arthritis $(n=5 ; 38,5 \%)$, low complement 
$(n=4 ; 31 \%)$, dsDNA $(n=4 ; 31 \%)$; with a medium dose of $10 \mathrm{mg}$ prednisolone/ day and $265 \mathrm{mg} /$ day of hydroxychloroquine. Post-vaccination mean SLEDAI was 5.8 : due to arthritis $(n=6 ; 46 \%)$, rash $(n=5 ; 38,5 \%)$ and low complement $(n=6 ; 46 \%)$; with a medium dose of $8 \mathrm{mg}$ prednisolone/day and $288 \mathrm{mg} /$ day of hydroxychloroquine. There was not a difference in organ involvement before and after vaccination, but rash was slightly more prevalent after vaccination. Conclusion: In our population, HPV vaccination didn't significantly change disease activity and organ involvement or mean dose need of prednisolone or hydroxychloroquine. Although it is a small size SLE sample, it suggests that is safe to administer HPV vaccination to SLE patients.

References: [1]eularSegal Yahel, Zabludowicz Center for Autoimmune Diseases, Tel Aviv (2017), "HPV and systemic lupus erythematosus: a mosai of potential crossreaction", SLE Research and Clinical Update, 23 January 2017

[2]Geier David Institute of Chronic Illnesses, USA, (2016), "Quadrivalent human pappilomavirus vaccine and autoimmune adverse events: a case-control assessment of the vaccine adverse event reporting system (VAERS) database, Environment and Autoimmunity, 13 July 2016

Disclosure of Interests: : None declared

DOI: 10.1136/annrheumdis-2020-eular.4816

\section{AB0407 1 HUMAN PAPILLOMA VIRUS (HPV) INFECTION AND CERVICAL CANCER PREVALENCE IN A PORTUGUESE UNIVERSITY HOSPITAL SINGLE-CENTER SYSTEMIC LUPUS ERYTHEMATOSUS COHORT}

\begin{abstract}
J. Sousa Morais ${ }^{1}$, D. G. Oliveira ${ }^{2}$, R. Faria ${ }^{3,4}$, A. Almeida $^{3}$, M. Brandão ${ }^{3,4}$, A. Marinho ${ }^{3,4}$, I. Almeida ${ }^{3,4}$, F. Farinha ${ }^{3}$, C. Vasconcelos ${ }^{3,4}$. ${ }^{1}$ Serviço de Medicina, Braga, Portugal; ${ }^{2}$ Serviço de Medicina, Porto, Portugal; ${ }^{3}$ Unidade de Imunologia Clínica, Porto, Portugal; ${ }^{4}$ Abel Salazar Biomedical Sciences Institute - University of Porto, UMIB, Porto, Portugal
\end{abstract}

Background: About $12 \%$ of women worldwide are infected with Human Papillomavirus (HPV), the most frequent cause of cervical cancer (CC) - very prevalent $(\sim 7,5 \%)$ and preventable. National screening efforts are in use in several countries, including Portugal. Patients with Systemic Lupus Erythematosus (SLE) are at increased risk of HPV infection and CC when compared to the healthy population.

Objectives: To evaluate the prevalence of HPV infection and rate of incidence of cervical neoplastic lesions in a SLE patient cohort followed at a university hospital.

Methods: Retrospective single-center (35 year long, 463 SLE patient cohort) review of all female SLE patients' local and online national health care records on $\mathrm{HPV}$ vaccination and CC screening.

Results: Of the 463 SLE patients, 420 were women (91\%), of which 322 had records on of HPV infection or CC developed. Mean patients' current age was 48 years and all had screening for cervical pathology in the last 3 years. Thirtythree patients $(11 \%)$ had HPV infection diagnosed at a mean age of 44 years. Twenty-seven (8\%) of SLE patients were vaccinated for HPV: $8(22 \%)$ of the infected patients had the vaccine, half after the HPV infection. Despite HPV infection, 49 patients (15\%) had developed some cervical lesion, of which 41 ( $84 \%$ of cervical lesion) were suggestive of malignancy, and ultimately CC was diagnosed in 20 women ( $41 \% ; 6 \%$ of total women), with a mean age at diagnosis of 45 years. All CC patients had history of HPV infection, but only 3 women ( $15 \% ; 0,9 \%$ of total women) had been vaccinated against HPV, 2 after the diagnoses of CC and 1 before.

Conclusion: In our population the prevalence of HPV was higher than reported for the general population using the World Health Organization database, conforming the higher risk of HPV infection in SLE patients. The prevalence of cervical cancer, however, was similar to the healthy population.

References:

[1] https://www.who.int/immunization/diseases/hpv/en/

[2]Forman David (2012); "Global Burden of Human Papillomavirus and Related Diseases", Vaccine, Elsevier Volume 30, Supplement 5, 20 November 2012 [3]Grein Ingrid (2016), Department of Pediatric Immunology and Rheumatology, Netherland (2016), HPV infection and vaccination in Systemic Lupus Erythematosus patients: what we really should know, Pediatric Rheumatology, 2016

Disclosure of Interests: : None declared

DOI: 10.1136/annrheumdis-2020-eular.5181

\section{AB0408 DOES THE PRESENCE IN THE SERUM OF ANTIPHOSPHOLIPID ANTIBODIES CORRELATE WITH SPECIFIC/NON SPECIFIC CAPILLAROSCOPIC ABNORMALITIES?}

G. Ferrari ${ }^{1}$, S. Paolino ${ }^{1}$, A. Sulli ${ }^{1}$, C. Pizzorni ${ }^{1}$, G. Pacini ${ }^{1}$, E. Gotelli ${ }^{1}$, A. Lercara ${ }^{1}$, V. Smith ${ }^{2}$, M. Cutolo'. ${ }^{1}$ Research Laboratory and Academic Division of Clinical Rheumatology, Department of Internal Medicine, University of Genova, IRCCS San Martino Polyclinic, Genova, Italy; ${ }^{2}$ Department of Internal Medicine, Ghent University; Department of Rheumatology, Ghent University Hospital; Unit for Molecular Immunology and Inflammation, VIB Inflammation Research Center, Ghent, Belgium

Background: Antiphospholipid syndrome (APS) is a systemic autoimmune disease characterized by specific vascular and obstetric manifestations and by antiphospholipid antibodies (aPL) positivity [1].

To date, little is known regarding nailfold videocapillaroscopy (NVC) alterations in APS patients and in asymptomatic aPL-carriers, non-specific abnormalities being the most frequently reported $[2,3,4]$.

Objectives: To retrospectively analyze NVC alterations in APS patients and in asymptomatic aPL-carriers and to correlate NCV alterations with both clinical manifestations and serum aPL profile.

Methods: Thirty-five aPL positive patients having received at least one NCV inves tigation (mean age 47 years, range 16-81, 31 female and 4 male) were retrospectively included in the study. For each patient complete medical history was collected with a particular attention to past vascular thrombosis and pregnancy morbidity. Patients were classified as affected by APS according to the updated Sapporo classification criteria [5]. Lupus anticoagulant (LAC), IgM and IgG anti-cardiolipin antibodies (ACL) and IgM and IgG anti-Beta2 Glycoprotein 1 (anti-B2GP1) were assessed in each patient according to the recommended procedures [5]. NCV parameters were analyzed in each patient, with a particular interest to hemorrhages or nailfold bed-parallel hemosiderin deposits ("comb-like" hemorrhages) presence $[2,6]$. Statistical analysis was performed by parametric and non-parametric tests. Results: Seventeen patients (mean age 49 years, range 16-81 years) were asymptomatic aPL-carriers and 18 (mean age 46 years, range 26-71 years) were affected by APS. Within APS patients, 16 had a history of vascular thrombosis and 2 had pregnancy morbidity; in 6 patients APS was secondary to other autoimmune rheumatologic conditions ( 3 to Systemic Lupus Erythematosus, 2 to vasculitides and 1 to Mixed Connective Tissue Disease).

Among the total number of aPL-carriers and APS patients six patients showed a normal NVC pattern, 24 patients had non-specific NVC abmormalities and 5 patients had a "scleroderma-like" pattern. Interestingly, NCV microhemorrhages were significantly more frequent in APS patients than in asymptomatic aPL-carriers, both in score and in absolute ( $p=0.05$ and $p=0.04$, respectively). Particularly, in APS patients "comb-like" hemorrhages had a statistically significant higher prevalence than isolated hemorrhages $(p=0.03)$. Dilated capillaries score was significantly higher in APS patients than in asymptomatic aPL-carriers $(p=0.01)$. Not any statistically significant difference was observed regarding other capillary parameters (score of giant capillaries, loss of capillaries, or anormal shpaes, i.e. angiogenesis). Not any statistical correlation was observed between NVC parameters and different $\mathrm{aPL}$ profile.

Conclusion: The study shows that the total number of microhemorrhages and in particular the "comb-like" subtype, are significantly the most frequent specific abnormalities in APL patients when compared to asymptomatic aPL carriers. The presence of the "scleroderma like" NVC pattern may suggest a concomitant overlap syndrome. Not any correlation was found between aPL profile and other NVC parameters. Further studies need to develop a more specific APS NVC pattern for APS patients.

\section{References:}

[1] Tektonidou MG, et al RMD Open 2019; 5(1);

[2] Cutolo M, Elsevier 2010, pp141-143;

[3] Candela M, et al.1998:444-9;

[4] Aslanidis S, et al. Clin Exp Rheumatol 2011, 29:307-9;

[5] Miyakis S, et al. J Thromb Haemost 2006, 4:295-306;

[6] Cutolo M, et al Best Pract Res Clin Rheumatol 2008, 22:1093-108

Disclosure of Interests: : Giorgia Ferrari: None declared, Sabrina Paolino: None declared, Alberto Sulli Grant/research support from: Laboratori Baldacci, Carmen Pizzorni: None declared, Greta Pacini: None declared, Emanuele Gotelli: None declared, Adriano Lercara: None declared, Vanessa Smith Grant/research support from: The affiliated company received grants from Research Foundation - Flanders (FWO), Belgian Fund for Scientific Research in Rheumatic diseases (FWRO), Boehringer Ingelheim Pharma $\mathrm{GmbH} \& \mathrm{Co}$ and Janssen-Cilag NV, Consultant of: Boehringer-Ingelheim Pharma GmbH \& Co, Speakers bureau: Actelion Pharmaceuticals Ltd, Boehringer-Ingelheim Pharma GmbH \& Co and UCB Biopharma Sprl, Maurizio Cutolo Grant/research support from: Bristol-Myers Squibb, Actelion, Celgene, Consultant of: Bristol-Myers Squibb, Speakers bureau: Sigma-Alpha

DOI: 10.1136/annrheumdis-2020-eular.4881

\section{AB0409 \\ APL PREVALENCE IN WOMEN WITH LATE PREGNANCY COMPLICATION AND LOW-RISK FOR CHROMOSOMAL ABNORMALITIES}

S. G. Foddai ${ }^{1}$, M. Radin $^{1}$, I. Cecchi ${ }^{1}$, E. Rubini ${ }^{1}$, S. Gaito ${ }^{1}$, L. Marozio ${ }^{1}$, T. Manetta ${ }^{1}$, G. Mengozzi ${ }^{1}$, S. Sciascia ${ }^{1}$, D. Roccatello ${ }^{1} .{ }^{1}$ University of Turin, Turin, Italy 